\title{
A BIBLIOMETRIC ANALYSIS ON ETHICAL CLIMATE
}

\author{
Wan Zairibahri Wan Abdul Razak ${ }^{1}$, Norizah Mohd Mustamil ${ }^{2}$ \\ ${ }^{1}$ Department of Business Policy \& Strategy, Faculty of Business \& Accountancy, \\ University of Malaya, Malaysia \\ ${ }^{2}$ Head of Department of Business Policy \& Strategy, Faculty of Business \& Accountancy, \\ University of Malaya. Kuala Lumpur, Malaysia
}

\begin{abstract}
The purpose of this study is to retrieve and explore past studies done on ethical climate. A search using the bibliometric analysis method was made on the Web of Science (WoS) database for publications of between 1970 until 2020. The VOS Viewer software was used to retrieve and explore numerous aspects of these publications, such as author keywords, bibliographic coupling of the publications, journals, countries, and authors. Analysis indicated that the most prominent publication was, "Bad Apples, Bad Cases and Bad Barrels: Meta-Analytic evidence about sources of unethical decision at work" authored by KishGephant, Harrison and Trevino (2010). It was also noted that the journal with the most impact was the Journal of Business Ethics followed by the journal of Nursing Ethics. The prominent countries engaged in ethical climate publications were: the USA, China and Turkey, in that order. Analysis also showed that the most prominent authors/researchers were Borhani and Fariba, with eight articles. In examining the concepts that were associated with ethnical climate, it was identified that ethical leadership, moral distress, organizational climate and employee burnout were the most frequently studied.
\end{abstract}

Key words: Ethical Climate, Bibliographic Coupling, Visualization, Web of Science

\section{INTRODUCTION}

Ethical climate was theorized by Victor and Cullen [1]1988) who defined ethical climate as "the shared perceptions of what ethically correct behaviour is and how ethical issues should be handled". This definition further defined by Viswesvaran, Chockalingam, \& Deshpande [2] (1996) and Kohlberg [3] (1981) as the common view of dissimilar moral values with dissimilar standards that can be challenging. The latest definition of ethical climate was by Badrinarayanan, Ramachandran, \& Madhavaram [4] (2018) were ethical climate reflects employees perceptions of morally appropriate actions and policies prevailing in their workplace in sales person context. Kadicmaglajlic, Milena, Nick, Boso, and Irena [5] (2017) in their study, had emphasized on industry-specific norms and values that are important in the ethical climate of industries.

When examining the nursing context, Asgari, Shafipour, and Taraghi [6] (2017, p.2) defined ethical climate as, "part of space or an organizational culture that affects not only the critical dimension of the employees, but also their work efficiency". Hung and Tsai [7] (2016) proposed that ethical climate is the mutual view of practices and procedures within organizations; it is the measurement used to understand the climate in an organization that has specific rules and procedures. The practices reflect decision - making and moral consequences.

In their systematic review, Newman, Round, Bhattacharya and Roy [8] (2017) revealed that ethical climate has a significant relationship with various antecedents and outcomes factors. The study by Gumusluoglu, Karakitapoğlu-Aygün, and $\mathrm{Hu}$ [9] (2019) revealed that benevolent and authoritarian leadership is an important aspect in influencing the ethical climate (justice perceptions) in three different countries - Taiwan, Turkey and the USA. It appears that if moral distress is identified, and eventually eliminated, the ethical climate for the nursing context would also improve. This then leads to a higher quality care for the patients. Ethical leadership also exhibited some degree of significance in the aviation maintenance centers in Turkey [10]. Likewise, ethical leadership helped to improve the level of job satisfaction among staff in 
the Chinese Insurance companies in Bosnia and Herzegovina [11].

Ethical climate can also develop different organizational outcomes, such as job satisfaction, organizational deviance, or even turnover intention. Asgari et al. [12] (2017) noted that an improved ethical climate can enhance job satisfaction among nurses in the medical context. In their study, Joe, Hung, Chiu, Lin, and Hsu [13] (2018) followed by Mulki and Lassk [14] (2019) observed that an improved ethical climate can result in fewer turnover intentions. Nonetheless, Hsieh and Wang [15] (2016) noted that ethical climate was not significant with organizational deviance among employees in electronics companies in Taiwan.

The current study aims to retrieve and explore past studies done on ethical climate so as to highlight the impact of ethical climate on organizations, hence contribute to literature. In this regard, a bibliometric analysis approach was used to explore and analyze various aspects of the articles retrieved.

"Bibliometrics" is one of the quantitative analytical method used to measure the recorded communications, and to explore numerous characteristics of the article [16]. This quantitative analytical method is very helpful for understanding the specific articles, the disciplines, fields and areas of study, such as citation numbers and citations, both of which have been cited to be difficult procedures [17]. The bibliometrics method offers valuable information such as the characteristics of the articles in terms of keywords, institutions, journals, countries, and authors [18]. With the advancement of computer technology and analytical tools such as the VOS Viewer which uses "Visualization", the bibliometrics analytical approach has been expanded to become a more specific methodology for data visualization purposes. For instance, the bibliographic coupling of publications, institutions, journals, countries, co-occurrences of author keywords and co-citation networks [19].

The Web of Science is noted as a popular research platform among researchers in the area of science, arts and humanities. Since its establishment in 1964 by Eugene Garfield, this platform has currently become a favorite among researchers because of the huge journal index, subject categories, and cited references [20]. Citation index is hereby described as an "ordered list of cited articles, each of which is accompanied by a list of citing articles" [21]. Hence, this paper used the Science Citation Index (SCI) in the Web of Science for retrieving the core collection of the database on ethical climate.

\section{METHODOLOGY}

This study uses the bibliometric analysis method which is a quantitative approach to identify and to reveal the trend and structure of the publications done within the discipline of ethical climate [22]. The Web of Science (WoS) database was utilized because of its extensive scientific publications which are consistent and valid [23].

To pursue the data screening, the Web of Science core collection database was then searched for all the past publications. A check was made for all the indexes, and the time range was kept for all years, ranging from 1970 to February 2020. The keywords, "Ethical Climate" were searched in the topic category. Other searched terms are given below in the box.

You searched for: TOPIC: ("ethical work climate") OR TOPIC: ("Ethical Climate")

Timespan: All years. Indexes: SCI-EXPANDED, SSCI, A\&HCI, CPCI-S, CPCI-SSH, BKCI-S, BKCISSH, ESCI.

The VOS Viewer, which is a bibliometric software, was then used to conduct the analysis. Zupic and Čater [24] (2015) had explained that 'bibliometrics' is a quantitative tool/measure used for analyzing the various elements/characteristics/aspects of the publications. These encompass elements like: journal, author, keywords, countries, citations, and co-authors, year, titles and others. Bibliographic coupling is basically similar to the co-citation method. It analyzes citations as a means to establish the relatedness between documents. Bibliographic coupling works by detecting any two articles that have commonly cited a third document. This strategy is an indication that a probability exists such that the two works had commonly treated a separate but related subject matter. Two documents are thus considered to be bibliographically coupled if they both commonly cited one or more documents.

\section{PUBLICATION TIMELINE}

A total of 702 scientific articles were extracted as a result of searching for the keywords. These publications were then manually checked for duplications or irrelevancy to the analysis. The table below shows the publications based on year. 
Table 1. Publication Per Year

\begin{tabular}{ccc}
\hline Publication Years & Records & \% of 702 \\
\hline 2020 & 8 & 1.14 \\
2019 & 94 & 13.39 \\
2018 & 87 & 12.393 \\
2017 & 74 & 10.541 \\
2016 & 54 & 7.692 \\
2015 & 75 & 10.684 \\
2014 & 39 & 5.556 \\
2013 & 34 & 4.843 \\
2012 & 32 & 4.558 \\
2011 & 30 & 4.274 \\
2010 & 22 & 3.134 \\
2009 & 30 & 4.274 \\
2008 & 22 & 3.134 \\
2007 & 14 & 1.994 \\
2006 & 4 & 0.57 \\
2005 & 9 & 1.282 \\
2004 & 8 & 1.14 \\
2003 & 3 & 0.427 \\
2002 & 10 & 1.425 \\
2001 & 8 & 1.14 \\
2000 & 8 & 1.14 \\
1999 & 8 & 1.14 \\
1998 & 3 & 0.427 \\
1997 & 8 & 1.14 \\
1996 & 6 & 0.855 \\
\hline
\end{tabular}

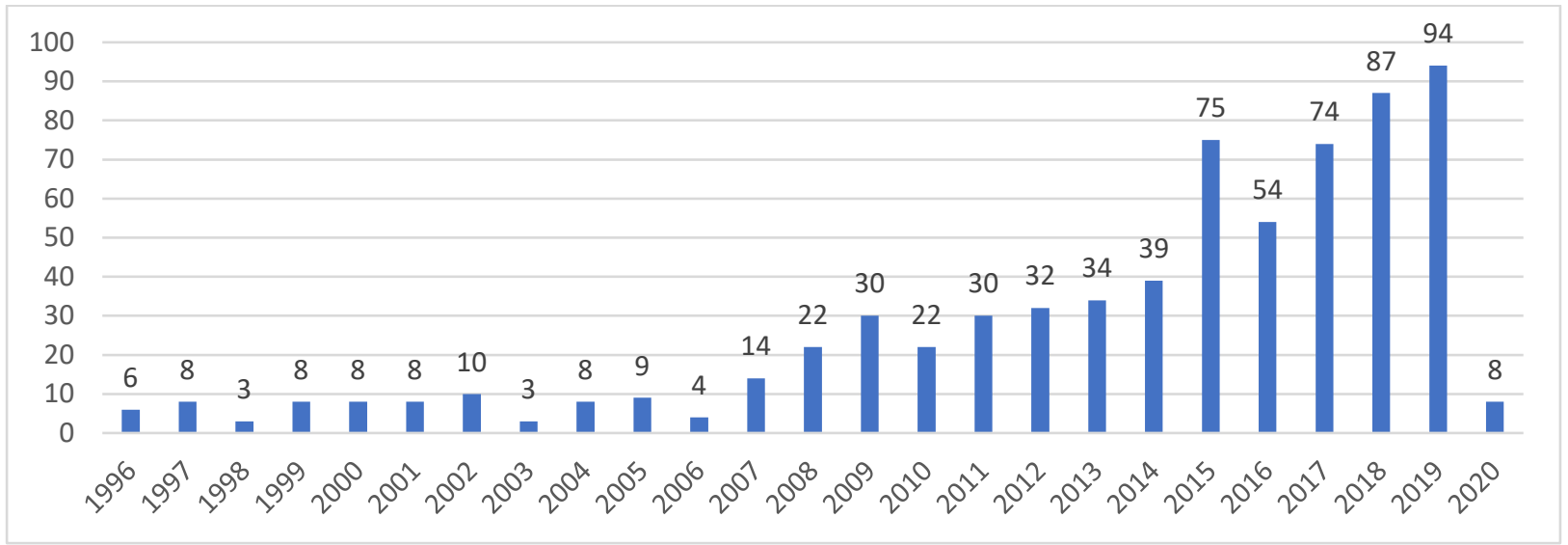

Figure 1. Publication Per Year

The outcome of the analysis showed that initial works looking at ethical climate began in 1996. From 1997 to 2006, the annual (per year) publication on ethical climate was less than 11 publications per year. From 2007 onwards, research on ethical climate began to gain momentum, and in 2019, this area reached its maximum number of publications, totalling 94. This trend shows that ethical climate is currently a research area that has gained the attention of researchers. 


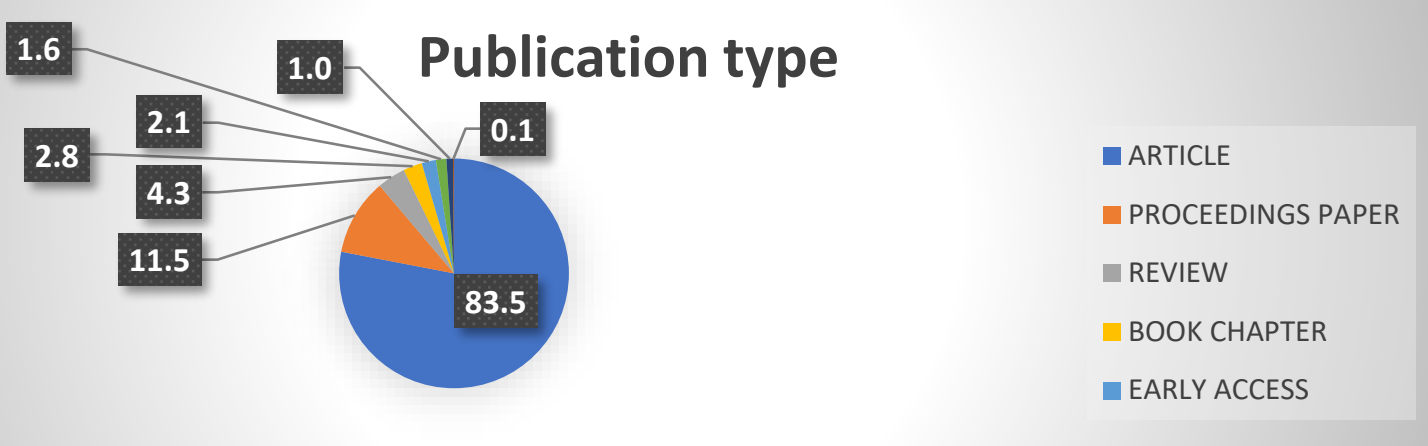

Figure 2. Publication Type

The Pie chart provided illustrates the major type of publications in the Web of Science core collection database. It was noted that research looking at ethical climate was published in $83.5 \%$ articles, $11.5 \%$ proceeding papers, and $4.3 \%$ review papers.

\section{TOP JOURNALS IN THE FIELD}

The bibliographic coupling algorithm was then used with the unit of analysis sources (journals) so as to locate the top and strongest linked journal in the field of ethical climate research. Analysis showed that the least number of publications on 'ethical climate' was set at three publications. The table shows the top 15 journals in the field of ethical climate research. Among these, the Journal of Business Ethics was at the top, comprising 144 publications, 7190 citations, and a total link strength 18965 . This is followed by the journal of Nursing Ethics which consists of 57 publications, 1164 citations, and 6697 total link strength. The next in line was the Journal of Business Research harnessing 13 publications, 524 citations, and 4379 total link strength. The analysis further indicated that in the Web of Science, journals carrying aims and scopes on ethics were among the top journals for publications, that looking at ethical climate research.

Table 2. Top Journals

\begin{tabular}{lccc}
\hline \multicolumn{1}{c}{ Sources } & Documents & Citations & $\begin{array}{c}\text { Total link } \\
\text { strength }\end{array}$ \\
\hline Journal of business ethics & & 7190 & 18965 \\
Nursing ethics & 144 & 1164 & 6697 \\
Journal of business research & 57 & 524 & 4378 \\
Social behavior and personality & 13 & 36 & 2240 \\
Ethics \& behavior & 8 & 57 & 1695 \\
Business ethics-a european review & 7 & 27 & 2264 \\
International journal of human resource & 6 & 54 & 2590 \\
management & 6 & 79 & 2801 \\
Journal of personal selling \& sales management & & 3 & 1798 \\
Personnel review & 6 & 197 & 2031 \\
Psychological reports & 5 & 384 & 398 \\
Critical care medicine & 5 & 23 & 118 \\
Intensive care medicine & 4 & 556 & 2280 \\
Journal of applied psychology & 4 & 15 & 732 \\
Journal of business \& industrial marketing & 4 & 6 & 7 \\
World neurosurgery & 4 & 4 & \\
\hline
\end{tabular}

\section{KEYWORD ANALYSIS}

The co-citation algorithms were used to identify the top keywords used by authors. The minimum value for the occurrence of author keywords was defaulted at 5. Of the total of 1691 keywords that fulfilled the threshold, the analysis showed different cluster emergence. This was based on the concept of cooccurrences in the research on ethical climate. The most prominent cluster consisted of keywords such as ethical climate, which also appeared to be the strongest keyword noted in the research on ethical climate. This was followed by other keywords, such as ethical leadership, moral distress, organizational 
climate, burnout, and professional ethics. Another strong cluster had emerged under other keywords which were represented in red in the table provided. They include: organizational commitment, job satisfaction, turnover intention, job performance, and perceived organizational commitment. The third cluster that surfaced in this analysis contained keywords which have been indicated in blue. They encompass words like: trust, integrity, corruption, nursing ethics, and organizational ethics. The fourth cluster was presented in purple. They include keywords such as: ethical behavior, ethical climate questionnaire, service climate, business ethics, and organizational culture.

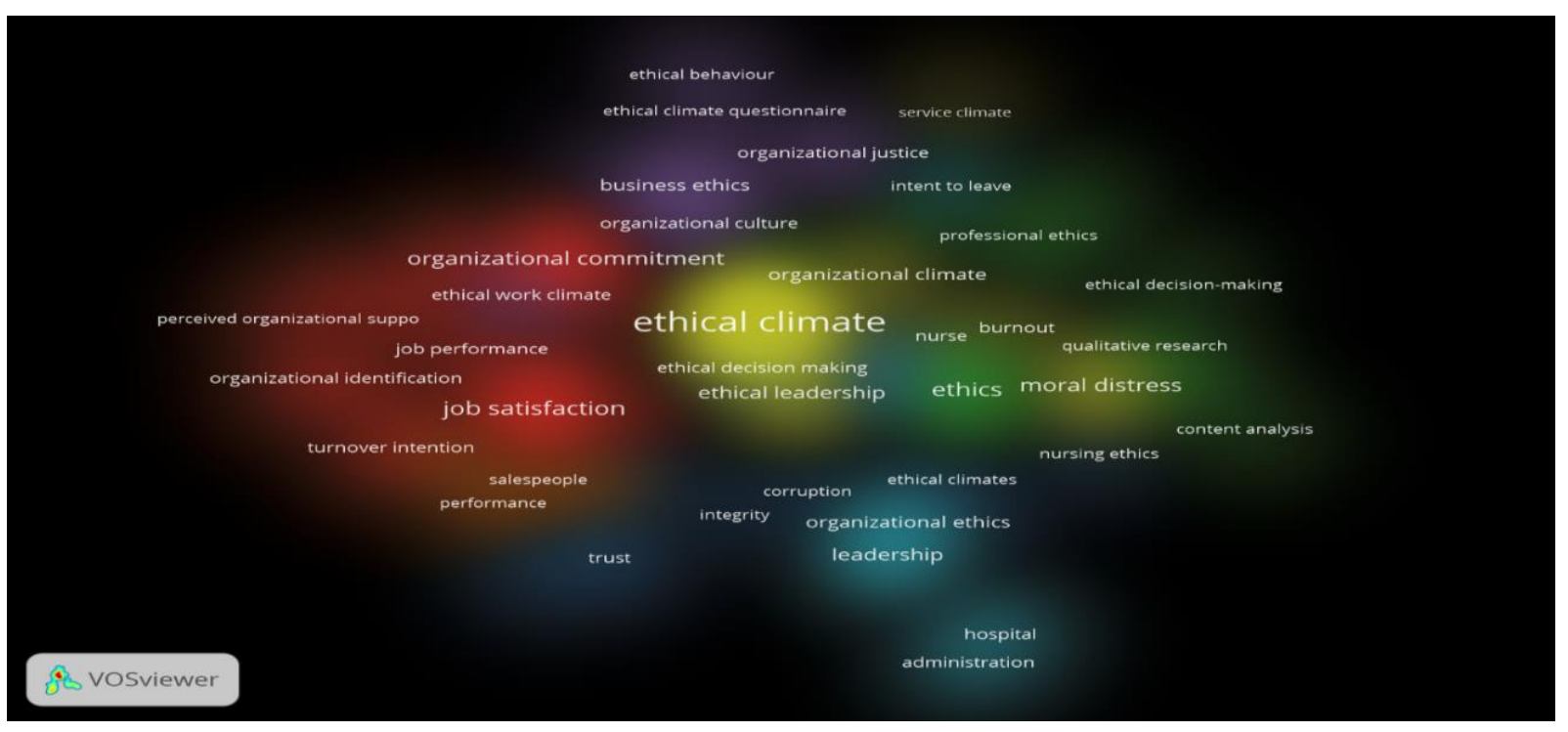

Figure 3. Keywords Density Visualization

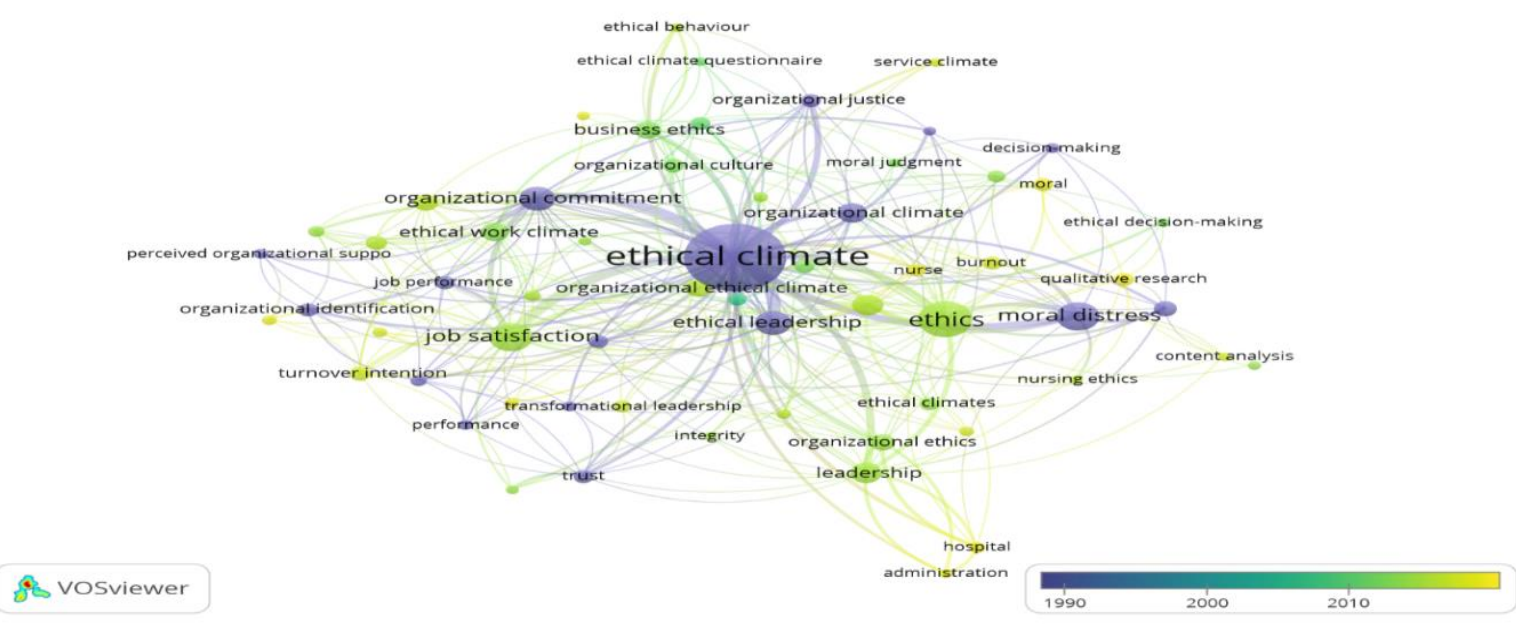

Figure 4. Overlay Visualization of Keywords

The figure projecting the visualization shows that the blue keywords were among the earliest works done in ethical climate. These works had focused on concepts such as: perceived organizational support, moral distress, organizational commitment, organizational justice, ethical behavior, trust, ethical climate questionnaire, and job performance. In contrast, the yellow keywords represent the more recent works done on ethical climate. Here, 
the authors were mainly looking at variables such as: leadership, turnover intention, hospital administration, nursing ethics, organizational identification, and organizational ethical climate.

\section{TOP AUTHORS IN THE FIELD}

The bibliographic coupling analytical approach was next used to explore authors with the highest number of publications, highest citations, and the strongest total link strength. The minimum value for author publication was set at 5. Out of 1692 authors, only 10 had fulfilled this threshold. The table below further illustrates.

Table 3. Top Authors in the Field

\begin{tabular}{lccc}
\hline Author & Documents & Citations & Total Link Strength \\
\hline Borhani, Fariba & 8 & 59 & 508 \\
Abbaszadeh, Abbas & 7 & 44 & 475 \\
Jaramillo, Fernando & 6 & 77 & 313 \\
Shapira-Lishchinsky, Orly & 6 & 67 & 282 \\
Charalambous, Andreas & 5 & 28 & 415 \\
Deshpande, Satish P. & 5 & 184 & 273 \\
Kim, Byung-Jik & 5 & 9 & 829 \\
Kim, Tae-Hyun & 5 & 9 & 829 \\
Silen, Marit & 5 & 89 & 256 \\
Willem, Annick & 5 & 18 & 194 \\
\hline
\end{tabular}

The author with the highest publication in the field of ethical climate was traced to Borhani, Fariba, with a total of eight (8) publications, and 59 citations. The author with the most citations was identified as Deshpande, and Satish P., with a total of 184 citations. The author with the strongest total link strength of 829 were Kim, ByungJik and Kim,Tae-Hyun.

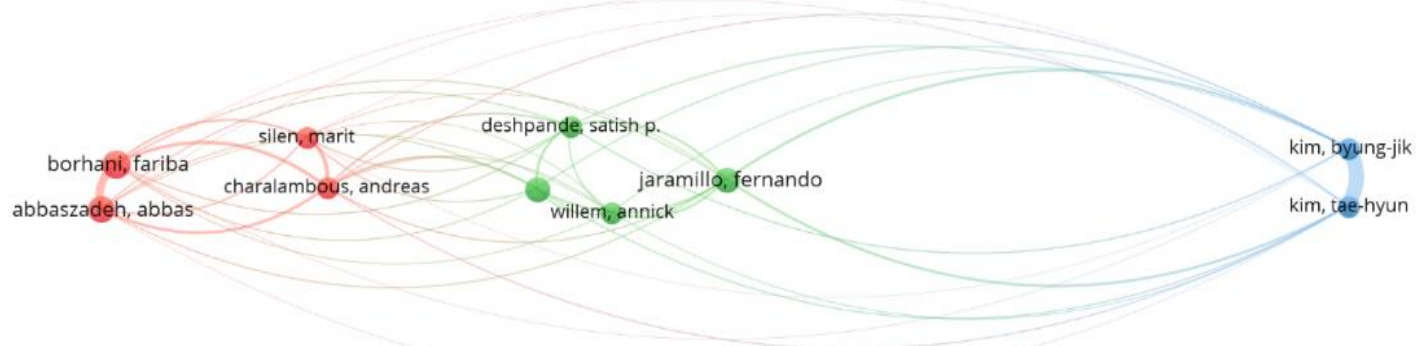

Figure 5. Network Visualization of Authors 
The network visualization based on author bibliographic coupling shows that there are three cluster emerging on the basis of author's collaboration and co citations. Cluster one in red color, cluster 2 in green color and cluster 3 in blue color.

\section{TOP PUBLICATIONS IN THE FIELD}

The bibliographic analysis using document as unit of analysis to find out the top publication, with highest citation and strongest total link strength. The minimum citation per publication was set at 100 , out of 702 publication, 36 met the threshold of 100 citations. The strongest publication with highest 535 citations is 'Bad Apples, Bad Cases, and Bad Barrels: Meta-Analytic Evidence About Sources of Unethical Decisions at Work' by Kish-Gephart, Harrison, \& Treviño [25] (2010) published in journal of applied psychology. The research focuses on why organizational member takes unethical decisions, and the research found some potential antecedents for unethical decision makings. The study finding provided useful insight and suggestion for ethical impulse perspective and ethical calculus perspective.
The second publication in the field with 353 citations is 'Nurse-physician perspectives on the care of dying patients in intensive care units: Collaboration, moral distress, and ethical climate' by Hamric and Blackhall [26] (2007) published in Critical Care Medicine. The study focuses on registered nurses experienced more moral distress and lower collaboration than physicians, they perceived their ethical environment as more negative, and they were less satisfied with the quality of care provided on their units than were physicians. Provider assessments of quality of care were strongly related to perception of collaboration. Improving the ethical climate in ICUs through explicit discussions of moral distress, recognition of differences in nurse/physician values, and improving collaboration may mitigate frustration arising from differences in perspective.

Table 4. Top Publication in the Field

\begin{tabular}{|c|c|c|}
\hline Documents & Citations & Total Link Strength \\
\hline Kish-Gephart (2010) & 535 & 218 \\
\hline Hamric (2007) & 353 & 19 \\
\hline Martin (2006) & 343 & 213 \\
\hline Schwepker (2001) & 272 & 171 \\
\hline Delmas (2011) & 263 & 23 \\
\hline Kuenzi (2009) & 246 & 112 \\
\hline Cullen (2003) & 240 & 113 \\
\hline Flannery (2000) & 223 & 91 \\
\hline Wimbush (1994) & 219 & 109 \\
\hline Grojean (2004) & 213 & 150 \\
\hline Neubert (2009) & 203 & 126 \\
\hline Schminke (2005) & 188 & 161 \\
\hline Pauly (2009) & 173 & 26 \\
\hline Mayer (2010) & 171 & 90 \\
\hline Koh (2001) & 167 & 56 \\
\hline Cullen (1993) & 165 & 66 \\
\hline Ulrich (2007) & 156 & 23 \\
\hline Schluter (2008) & 150 & 24 \\
\hline Vardi (2001) & 146 & 130 \\
\hline Sims (1992) & 146 & 26 \\
\hline Dickson (2001) & 141 & 159 \\
\hline Divaris (2008) & 129 & 0 \\
\hline Peterson (2002) & 129 & 124 \\
\hline Peterson (2002a) & 129 & 134 \\
\hline Barnett (2000) & 125 & 94 \\
\hline Mulki (2008) & 122 & 107 \\
\hline Wimbush (1997) & 120 & 114 \\
\hline Sims (1994) & 118 & 47 \\
\hline Tsai (2008) & 116 & 116 \\
\hline Ruppel (2000) & 114 & 62 \\
\hline
\end{tabular}


Wan Zairibahri \& Norizah / International Journal of Business and Management,4(2) 2020, Pages: 12-21

\begin{tabular}{lcc} 
Hart (2005) & 113 & 31 \\
Ambrose (2008) & 110 & 145 \\
Babin (2000) & 107 & 77 \\
Sims (2002) & 104 & 36 \\
Deshpande (1996) & 104 & 28 \\
Schwepker (1997) & 101 & 123 \\
\hline
\end{tabular}

\section{TOP COUNTRIES IN THE FIELD}

The bibliographic coupling analysis also uncovered countries with the highest publications, citations, and total link strength. Based on the co-citation analysis, and the density visualization, the clusters that emerged offered useful insights into the collaborations that exist between authors all over the world.

The top 19 countries were shortlisted by the software, based on the criteria of 10 publications as a threshold.

Table 5. Top Countries in the Field

\begin{tabular}{cccc}
\hline Country & Documents & Citations & Total Link Strength \\
\hline USA & 270 & 9870 & 118153 \\
China & 65 & 494 & 43338 \\
Turkey & 37 & 563 & 31623 \\
England & 34 & 627 & 22039 \\
Australia & 33 & 545 & 21456 \\
Canada & 33 & 748 & 17255 \\
Taiwan & 32 & 527 & 35480 \\
Malaysia & 25 & 176 & 18900 \\
Iran & 23 & 123 & 7110 \\
South Korea & 23 & 315 & 19397 \\
Israel & 20 & 383 & 15329 \\
Sweden & 18 & 227 & 7133 \\
Germany & 17 & 225 & 13617 \\
Belgium & 16 & 222 & 9564 \\
France & 16 & 289 & 10440 \\
Netherlands & 16 & 389 & 11227 \\
Finland & 15 & 119 & 9922 \\
Italy & 12 & 123 & 9437 \\
India & 10 & 26 & 10762 \\
\hline
\end{tabular}

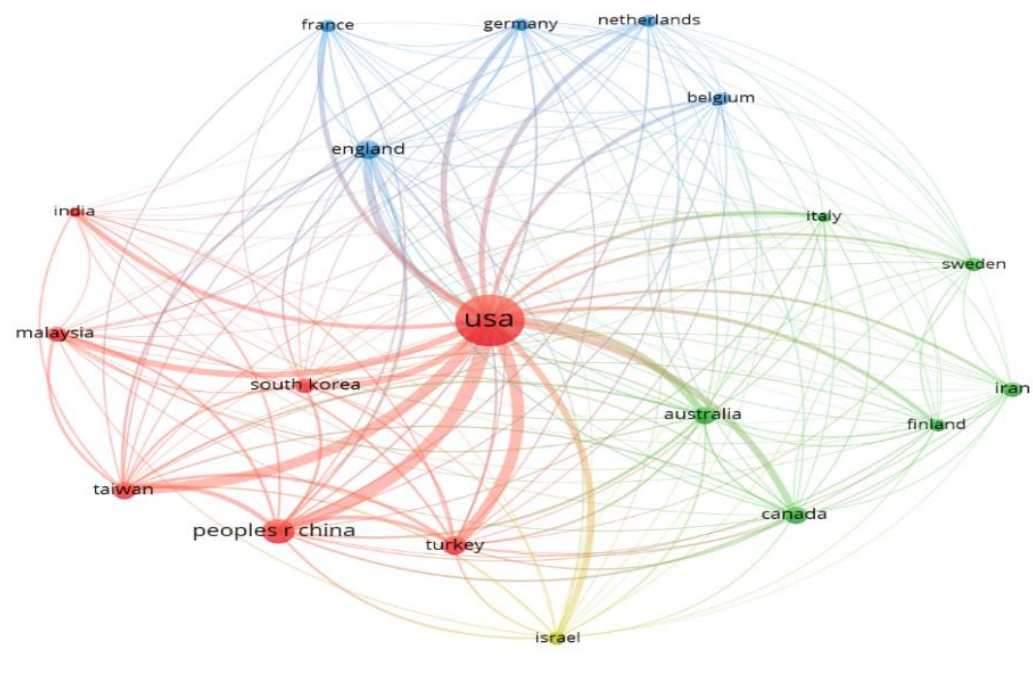

Figure 6. Network visualization of Countries 
The network visualizations, based on bibliographic coupling of countries, showed three clusters based on the network established between authors across the globe. Cluster one, in red, represents the USA, China, Turkey, South Korea, Malaysia, India and Taiwan. Cluster two, in blue, represents countries with collaborative research works, such as England, France, Germany, Netherland, Belgium, and Italy. Cluster three, in green, represents countries like Australia, Canada, Finland, Iran and Sweden.

\section{DISCUSSION}

The purpose of this paper was to identify and to explore the extent of research done in the field of ethical climate. The Web of Science core collection database was explored to find out the publications done in the field from 1970 until February 2020. This analysis had also attempted to uncover the key areas that researchers have focused on, the top journals, top authors, top countries and top publications in the field of ethical climate. Based on the bibliometric analysis approach, this paper was able to reveal that the field of ethical climate is very much under the focus of researchers, and the highest number of publications was observed in 2019. The journal of Business Ethics was among the top journal in the field whereas the journal of Nursing Ethics and the Journal of Business Research came in 2nd and 3rd, respectively. The keyword cooccurrences when used for analysis, also revealed that ethical climate research is now focusing on concepts such as: ethical leadership, moral distress, organizational climate, and employee burnout. With respect to the highest number of documents published in the research on ethical climate, the top author in the field was traced to Borhani, Fariba with eight publications. The strongest publication with the highest of 535 citations was traced to 'Bad Apples, Bad Cases, and Bad Barrels: Meta-Analytic Evidence About Sources of Unethical Decisions at Work' by Kish-Gephart, Harrison and Treviño [27] (2010). This was published in the Journal of Applied Psychology. Among the countries, the USA was noted to be the top country, with the highest total link strength, and highest number of publications, followed by China and Turkey, respectively.

\section{CONTRIBUTION, LIMITATION AND FUTURE RECOMMENDATION OF THE STUDY}

The major contribution of this research is the information extended to researchers about the current and updated status of ethical climate research. It outlines the research done within the field, the concepts most studied, and where the gap lies. This study also offers insight into all the publications done on the topic of ethical climate within the Web of Science core collection database, the top journals publishing in this area, and the key articles published thus far. This paper also emphasized on the prominent authors in the field, and the top country with the most impactful research.

The major limitation of this study lies in the source which is traced to the complete Web of Science database only. Future researchers may consider analyzing the same topic area and explore the Scopus database so as to make a comparison on the key elements of ethical climate research for both databases.

\section{REFERENCES}

[1] Victor, B. and Cullen, J. B. 1988. The Organizational Bases of Ethical Work Climates. Administrative Science Quarterly, 33(1): 101-125.

[2] Viswesvaran, Chockalingam. and Satish P. Deshpande, 1996. Ethics, Success, and Job Satisfaction: A Test of Dissonance Theory in India. Journal of Business Ethics, 15: 10651069.

[3] Kohlberg, L. 1981. Essays in Moral Development: The Philosophy of Thompson, $\mathrm{J}, \mathrm{D}$, Organizations in Action. New York: Harper \& Row.

[4] Badrinarayanan, V., Ramachandran, I. and Madhavaram, S. 2018. Mirroring the Boss : Ethical Leadership, Emulation Intentions, and Salesperson Performance. Journal of Business Ethics, 159: 897-912.

[5] Kadic-maglajlic, S., Milena, M., Nick, L., Boso, N. and Irena, V. 2017. Three Levels of Ethical Influences on Selling Behavior and Performance: Synergies and Tensions. Journal of Business Ethics, 156(2): 377-397.

[6] Asgari, S., Shafipour, V. and Taraghi, Z. 2017. Relationship between Moral Distress and Ethical Climate with Job Satisfaction in Nurses. Nursing Ethics, 26(2): 346-356.

[7] Hung, Y.-C. and Tsai, T.-Y. 2016. Ethical Work Climate and Organizational Citizenship Behavior in the Taiwanese Military. Military Psychology, 28(1): 34-49.

[8] Newman, A., Round, H., Bhattacharya, S. and Roy, A. 2017. Ethical Climates in Organizations : A Review and Research Agenda. Business Ethics Quarterly, 27(4): 475-512.

[9] Gumusluoglu, L., Karakitapoğlu-Aygün, Z. and $\mathrm{Hu}$, C. 2019. Angels and devils ?: How do Benevolent and Authoritarian Leaders 
Differ in Shaping Ethical Climate via Justice Perceptions Across Cultures?. Business Ethics: A European Review, 29(2): 388-402.

[10] Demirtas, O. and Akdogan, A. A. 2015. The Effect of Ethical Leadership Behavior on Ethical Climate, Turnover Intention, and Affective Commitment. Journal of Business Ethics, 130(1): 59-67.

[11] Fu, W. and Deshpande, S. P. 2015. The Impact of Caring Climate, Job Satisfaction, and Organizational Commitment on Job Performance of Employees in a China's Insurance. Journal Business Ethics, 124: 339349.

[12] Asgari, S., Shafipour, V. and Taraghi, Z. 2017. Relationship between Moral Distress and Ethical Climate with Job Satisfaction in Nurses. Nursing Ethics, 1-11.

[13] Joe, S.-W., Hung, W.-T., Chiu, C.-K., Lin, C.-P. and Hsu, Y.-C. 2018. To quit or not to Quit: Understanding Turnover Intention from the Perspective of Ethical Climate. Personnel Review, 47(5): 1062-1076.

[14] Mulki, J. and Lassk, F. G. 2019. Joint Impact of Ethical Climate and External Work Locus of Control on Job Meaningfulness. Journal of Business Research, 99: 46-56.

[15] Hsieh, H. and Wang, Y. 2016. Linking Perceived Ethical Climate to Organizational Deviance: The Cognitive, Affective, and Attitudinal Mechanisms. Journal of Business Research, 69(9): 3600-3608.

[16] Pritchard, A. 1969. Statistical Bibliography or Bibliometrics. Journal of Documentation, 25(4): 348-349.

[17] Farajnezhad, M. and Ramakrishnan, S. A. L. 2020. A Bibliometric Research of Economic Study in World and Malaysia Perspective based on Web of Science Core Collection. Journal of Environmental Treatment Techniques, 8(1): 521-534.

[18] Karakus, M. 2017. Bibliometric Analysis of Ethical Leadership Research in Social Sciences. International Journal of Educations, Arts and Science, 3(7): 72-89.

[19] Saberi, M. K., Barkhan, S. and Hamzehei, R. 2019. A Bibliometric Study and
Visualization of Library Philosophy and Practice during 1998-2018. Library Philosophy and Practice Journal (e-Journal), 2565: 1-18.

[20] Farajnezhad, M. and Ramakrishnan, S. A. L. 2020. A Bibliometric Research of Economic Study in World and Malaysia Perspective based on Web of Science Core Collection. Journal of Environmental Treatment Techniques, 8(1): 521-534.

[21] Garfield, E. 1964, "Science Citation Index" New Dimension in Indexing. Science, 144(3619): 649-654.

[22] Cobo, M.J., Lopez-Herrera, A. G., HerreraViedma, E. and Herrera, F. 2011. An approach for Detecting, Quantifying, and Visualizing the Evolution of a Research Field. A Practical Application to the Fuzzy Stes Theory Field. Journal of Infometrics, 5(1): 146-166.

[23] Zhu, J., Song, L. J., Zhu, L., \& Johnson, R. E. 2019. Visualizing the Landscape and Evolution of Leadership Research. Leadership Quarterly, 30(2): 215-232.

[24] Zupic, I., \& Čater, T. 2015. Bibliometric Methods in Management and Organization. Organizational Research Methods, 18(3): 429-472.

[25] Kish-Gephart, J. J., Harrison, D. A., \& Treviño, L. K. 2010. Bad Apples, Bad Cases, and Bad Barrels: Meta-Analytic Evidence About Sources of Unethical Decisions at Work. Journal of Applied Psychology, 95(1): $1-31$.

[26] Hamric, A. B. and Blackhall, L. J. 2007. Nurse-physician Perspectives on the Care of Dying Patients in Intensive Care Units: Collaboration, Moral Distress, and Ethical Climate. Critical Care Medicine, 35(2): 422429.

[27] Kish-Gephart, J. J., Harrison, D. A., \& Treviño, L. K. 2010. Bad Apples, Bad Cases, and Bad Barrels: Meta-Analytic Evidence About Sources of Unethical Decisions at Work. Journal of Applied Psychology, 95(1): 1-31. 